\title{
Two heads are better than one?
}

\author{
Geoff Norman ${ }^{1}$
}

๑) Springer Nature B.V. 2019

The superiority of small group instruction over lectures is a mantra repeated over and over at faculty development workshops and conferences, almost any place that educators assemble. Typically, it is prefaced by a flat statement that "No one learns anything from lectures", which creates a serious case of cognitive dissonance, since the very folks who are proselytizing this "axiom" were likely to have received virtually all their own education (or not) from lectures.

Not surprisingly, the evidence about small group instruction, while fairly extensive, is far from uniform. Some evidence from systematic reviews showed that the effect size of small group instruction is moderate (Lipsey and Wilson 1993), however the control condition as not specified and as Cook (2009) showed any education (even lectures) is superior to no education. Moreover, some studies have shown a negative effect of small groups with non-expert tutors of about the same magnitude (Eagle et al. 1992; Davis et al. 1992).

A recent extensive review claimed, with evidence, that unguided instruction (discovery learning) is an inferior instructional strategy, and that worked examples are superior (Kirschner et al. 2006). This too was contested (Hmelo-Silver et al. (2007); Schmidt et al. (2007). Still whoever eventually turns out to be right, small groups are not the magic bullet for learning that they are purported to be.

However, small groups are not viewed only as a sine qua non for their educational effects. We have all grown up with the idea that any problem that is tough to solve can be solved better by a small group. "Let's get together and brainstorm that" is viewed as the solution to all ills. Books have been written about successful strategies for brainstorming. In the heyday of small groups, the sixties, where we did everything-EVERYTHING-in small groups, elaborate rituals called obscure names like "synectics" evolved to ensure that the small group would do everything just right. All of these were designed to get those creative juices going, unfettered by practical or theoretical constraints. And it was guaranteed that with everyone building on everyone else's ideas, wonderful things would happen.

There was a small fly in the ointment however. I distinctly remember reading a small book that reviewed the evidence. One study in particular really stripped off the emperor's clothes. They compared problem solutions on brainstorming groups to solutions by the same number and kind of people who were locked in separate rooms and forced to come up with them on their own. When you looked at solutions generated by

Geoff Norman

norman@mcmaster.ca

1 McMaster University, Hamilton, ON, Canada 
individuals left to their own devices, they had more (no surprise) and better (surprise) solutions than the brainstorming groups.

I fear you will have to take my word for it, in terms of this old study. However, the idea of leaving people alone to come up with ideas and then aggregating results has not been entirely lost. It is now called the "nominal group process"-that is, a group in name alone. Strategies have evolved to conduct such an approach over multiple iterations to arrive at a final optimal set of solutions. A recent review article (Van De and Delbecq 1971) comes to precisely the same conclusion:

...the optimal combination of group processes for a problem-solving committee is: (1) the use of nominal group processes for fact-finding, idea generation, or initial subjective probability estimation in the first phase of a committee's work; (2) the use of structured feedback and interacting discussion in the second phase; and

(3) nominal group voting for final independent individual judgments in the final phase.

However, these results have gone largely unnoticed. Conversely, some of the ideas about superiority of groups have been reborn recently as changes in the health care system result in more and more care being delivered by multidisciplinary groups like "health care teams." The National Academy of Medicine has, in fact, proposed that one solution to diagnostic errors is collaborative, team-based diagnosis (Ball et al. 2015).

Until recently, while there was lots of evidence that much health care was delivered in groups or teams, there was not much evidence that this was a good thing. But in March, a study appeared in JAMA that purported to show that group diagnosis was demonstrably superior to individual diagnosis. (Barnett et al. 2019). From the abstract:

...groups consistently outperformed individuals regardless of approach.... Groups from 2 users (77.7\% accuracy) to 9 users (85.5\% accuracy) outperformed individual specialists in their subspecialty $(66.3 \%$ accuracy; $P<.001)$.

These gains, based on large sample sizes, are truly impressive. It really wants you to rush out and demand that every diagnosis should be done by at least two physicians. What a pity that they're not true.

Here's what actually happened. The study involved an online platform "Human Dx" where physicians and residents could submit cases in standardized format and could also attempt to diagnose cases in the data bank. The paper states that "more than 14,000 users ... have made more than 230,000 contributions authoring and diagnosing cases." In this study, the investigators located cases with 10 or more respondents. They randomly sampled 10 attempts from the data base. They next determined whether a particular interaction was correct or incorrect based on whether the correct diagnosis (of the author) was in first 3 positions of the differential. They finally created "groups" of size 2-9, and computed a collective diagnosis for the group by weighting each diagnosis based on its order on the list form using a $1 / \mathrm{n}$ or $1 / \mathrm{n}^{2}$ rule. Finally, the average order for each diagnosis was computed (This is simply a calculation of the harmonic mean). Then if the correct diagnosis on the composite list was in the top 3, the "group" was correct. This was then compared to a random individual. (I confess that this may not be exactly right, because some of the description was a bit obscure).

It is notable, that the label "group" is nominal. There was no actual group process; only post hoc averaging of independent contributions. As such, it says nothing about the effectiveness of small groups; rather, it might be viewed as evidence that crowdsourcing works, which we already know. 
On a slightly more sophisticated level, it stands to reason that the average of " $\mathrm{n}$ " informed clinicians' estimates of probability is going to be closer to the truth than any single estimate, however you choose to aggregate them. That simply reflects the " $1 / \sqrt{ } \mathrm{n}$ " relation between the standard error of the mean and the standard deviation.

In short, the paper yields a robust answer to the wrong question. What they should have done is compare the accuracy of " $n$ " diagnoses obtained independently (using methods like the one they did use) to a single differential diagnosis obtained by consensus of a group of "n" who fought it out in a room.

Things have a way of popping up in multiple locations. Last month I holidayed with my wife of 50 years in Sri Lanka to celebrate this auspicious event. I happened to grab a copy of the international New York Times boarding an airplane. And there I spied an article reporting on a study that appeared in Nature that week, based on an analysis of " 65 million papers, patents and software products that span the period 1954-2014 and demonstrate that across this period smaller teams have tended to disrupt science and technology with new ideas and opportunities, whereas larger teams have tended to develop existing ones." (Wu et al. 2019). It seems that the inverse relation between group size and productivity is universal.

Finally, to confirm this finding by example, I sought out the original theoretical article proposing the Higgs boson, which was published by Peter Higgs, alone, in 1964 (Higgs 1964). I then located the article confirming the existence of the Higgs boson, which appeared in 2012 and had over 3000 authors (ATLAS Collaboration et al., et al., et al., ad infinitum ad nauseam).

To conclude, my title is almost right. A more accurate revision:

Two (Independent) Heads are Better Than One (Group of Two Heads).

\section{References}

ATLAS Collaboration et al. (2012). Observation of a new particle in the search for the Standard Model Higgs boson with the ATLAS detector at the LHC. Physics Letters B, 716, 1-29.

Ball, J., Balogh, E., \& Miller, B. T. (Eds.). (2015). Improving diagnosis in health care. Washington: National Academies Press.

Barnett, M., Boddupalli, D., Nundy, S., \& Bates, D. W. (2019). Comparative accuracy of diagnosis by collective intelligence of multiple physicians vs individual physicians. Journal of the American Medical Association, Network Open, 2(3), e190096. https://doi.org/10.1001/jamanetworkopen.2019.0096.

Cook, D. A. (2009). The failure of e-learning research to inform educational practice, and what we can do about it. Medical Teacher, 31(2), 158-162.

Davis, W. K., Nairn, R., Paine, M. E., Anderson, R. M., \& Oh, M. S. (1992). Effects of expert and nonexpert facilitators on the small-group process and on student performance. Academic Medicine, 67, $470-474$.

Eagle, C. J., Harasym, P. H., \& Mandin, H. (1992). Effects of tutors with case expertise on problem-based learning issues. Academic Medicine, 67, 465-469.

Higgs, P. W. (1964). Broken symmetries and the masses of gauge bosons. Physical Review Letters, 13(16), 508.

Hmelo-Silver, C. E., Duncan, R. G., \& Chinn, C. A. (2007). Scaffolding and achievement in problem-based and inquiry learning: A response to Kirschner, Sweller, and. Educational Psychologist, 42(2), 99-107.

Kirschner, P. A., Sweller, J., \& Clark, R. E. (2006). Why minimal guidance during instruction does not work: An analysis of the failure of constructivist, discovery, problem-based, experiential, and inquirybased teaching. Educational Psychologist, 41(2), 75-86.

Lipsey, M. W., \& Wilson, D. B. (1993). The efficacy of psychological, educational, and behavioral treatment: Confirmation from meta-analysis. American Psychologist, 48(12), 1181. 
Schmidt, H. G., Loyens, S. M., Van Gog, T., \& Paas, F. (2007). Problem-based learning is compatible with human cognitive architecture: Commentary on Kirschner, Sweller, and. Educational Psychologist, 42(2), 91-97.

Van De, A., \& Delbecq, A. L. (1971). Nominal versus interacting group processes for committee decisionmaking effectiveness. Academy of Management Journal, 14(2), 203-212.

Wu, L., Wang, D., \& Evans, J. A. (2019). Large teams develop and small teams disrupt science and technology. Nature, 566, 378-382.

Publisher's Note Springer Nature remains neutral with regard to jurisdictional claims in published maps and institutional affiliations. 